\title{
Cryptogenic organising pneumonia or acute fibrinous and organising pneumonia?
}

\section{To the Editors:}

In a recent issue of the European Respiratory Journal, CHEE et al. [1] present a case that was diagnosed and treated as cryptogenic organising pneumonia. We have a few comments about this case.

First, histology is described as follows: "...diffuse intraalveolar exudate of granular, fibrinous material...". Organising pneumonia pattern, the histological hallmark of cryptogenic organising pneumonia, is characterised by intraalveolar buds of granulation tissue. Recently, a new anatomoclinical entity has been reported by BEASLEY et al. [2] as "acute fibrinous and organizing pneumonia (AFOP)". The clinical spectrum of this entity may be similar to cryptogenic organising pneumonia and, taking into account the morphological features on surgical lung biopsy specimens, in our opinion, the case reported by CHEE et al. [1] is more consistent with this diagnostic hypothesis.

Secondly, the diagnostic approach described in the paper by CHEE et al. [1] is dissimilar to that usually followed in our centre (GB Morgagni Hospital, Azienda USL di Forlì, Forlì, Italy). In patients with alveolar opacification shadows, bronchoscopy with bronchoalveolar lavage and transbronchial lung biopsy may contribute to a definitive diagnosis in $>60 \%$ of cases $[3,4]$, with fine-needle aspiration being less sensitive and specific [5].

\section{Poletti and G.L. Casoni}

GB Morgagni Hospital, Azienda USL di Forlì, Forlì, Italy.

\section{REFERENCES}

1 Chee CBE, Da Costa JL, Sim CS. A female with dry cough, progressive dyspnoea and weight loss. Eur Respir J 2005; 25: 206-209.

2 Beasley MB, Franks TJ, Galvin JR, Gochuico B, Travis WD. Acute fibrinous and organizing pneumonia: a histological pattern of lung injury and possible variant of diffuse alveolar damage. Arch Pathol Lab Med 2002; 126: 1064-1070.

3 Dina R, Sheppard MN. The histological diagnosis of clinically documented cases of cryptogenic organising pneumonia. Diagnostic features in transbronchial biopsies. Histopathology 1993; 23: 541-545.
4 The diagnosis, assessment and treatment of diffuse parenchymal lung disease in adults. Introduction. Thorax 1999; 54: Suppl. 1, 1-14.

5 Poletti V, Chilosi M, Olivieri D. Diagnostic invasive procedures in diffuse infiltrative lung diseases. Respiration 2004; 71: 107-119.

DOI: $10.1183 / 09031936.05 .00004805$

From the author:

We thank V. Poletti and G.L. Casoni for their comments and interest in our case report [1].

Acute fibrinous and organising pneumonia is certainly a possible differential diagnosis in our patient. However, the patient's subacute presentation, dramatic response to steroids and clinical course were more in keeping with, and indeed typical of, cryptogenic organising pneumonia. In contrast, in the original series by BEASLEY et al. [2], of 17 patients with the histological diagnosis of acute fibrinous and organising pneumonia, nine patients had a fulminant course with rapid progression to death. Of the seven patients in this series who were treated with steroids (with or without antibiotics), only two survived. It should also be noted that the histological diagnosis of acute fibrinous and organising pneumonia was made from open lung and autopsy specimens in all cases.

\section{C.B.E. Chee}

Tan Tock Seng Hospital, Singapore.

\section{REFERENCES}

1 Chee CBE, Da Costa JL, Sim CS. A female with dry cough, progressive dyspnoea and weight loss. Eur Respir J 2005; 25: 206-209.

2 Beasley MB, Franks TJ, Galvin JR, Gochuico B, Travis WD. Acute fibrinous and organizing pneumonia: a histological pattern of lung injury and possible variant of diffuse alveolar damage. Arch Pathol Lab Med 2002; 126: 1064-1070.

DOI: 10.1183/09031936.05.00020505

\section{The immune response to resistive breathing}

\section{To the Editors:}

The excellent review by VASsILAKOPOULOS et al. [1] discusses in detail the immune response to resistive breathing. The authors report the systemic effects of resistive breathing (cytokines in plasma), as well as the effects of resistive loads on the respiratory muscles (diaphragm). 